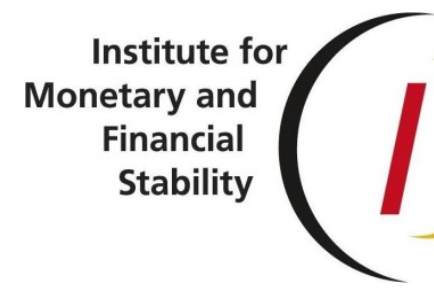

SEBASTIAN SCHMIDT

Optimal Monetary and Fiscal Policy with a Zero Bound on Nominal Interest Rates

Institute for Monetary and Financial Stability JOHANN WOLFGANG GOETHE-UNIVERSITÄT FRANKFURT AM MAIN 
Prof. Dr. Dr. H.c. Helmut Siekmann (HRSG.)

INSTITUTE FOR MONETARY AND FINANCIAL STABILITY

PROFESSUR FÜR GELD-, WÄHRUNGS- UND NOTENBANKRECHT JOHANN WOLFGANG GOETHE-UNIVERSITÄT

GRÜNEBURGPLATZ 1

60629 FRANKFURT AM MAIN

TELEFON: $\quad(069) 798-34014$

TELEFAX: (069) $798-33913$

E-MAIL: GELD-UND-WAEHRUNG@IMFS-FRANKFURT.DE 
Sebastian SchmidT

Optimal Monetary and Fiscal Policy with a Zero Bound on Nominal Interest Rates

Institute for Monetary and Financial Stability JOHANN WOLFGANG GOETHE-UNIVERSITÄT FRANKFURT AM MAIN 


\title{
Optimal Monetary and Fiscal Policy with a Zero Bound on Nominal Interest Rates *
}

\author{
Sebastian Schmidt ${ }^{\dagger}$ \\ Goethe University Frankfurt
}

May 30, 2012

\begin{abstract}
I characterize optimal monetary and fiscal policy in a stochastic New Keynesian model when nominal interest rates may occasionally hit the zero lower bound. The benevolent policymaker controls the short-term nominal interest rate and the level of government spending. Under discretionary policy, accounting for fiscal stabilization policy eliminates to a large extent the welfare losses associated with the presence of the zero bound. Under commitment, the gains associated with the use of the fiscal policy tool remain modest, even though fiscal stabilization policy is part of the optimal policy mix.
\end{abstract}

Keywords: $\quad$ Monetary policy, Fiscal policy, Discretion, Commitment, Zero nominal interest rate bound, New Keynesian model

JEL-Codes: $\quad \mathrm{E} 31, \mathrm{E} 52, \mathrm{E} 62, \mathrm{E} 63$

${ }^{*}$ I am grateful to Thomas Laubach, Ctirad Slavík, Volker Wieland, Matthias Burgert, and seminar participants at the University of Bonn and Goethe University Frankfurt for helpful comments. A previous version of this paper circulated under the title "Optimal Monetary and Fiscal Policy without Commitment and the Zero Nominal Interest Rate Bound." The usual disclaimer applies.

${ }^{\dagger}$ Mailing address: Goethe University, House of Finance, Grueneburgplatz 1, 60323 Frankfurt am Main; Email: s.schmidt@wiwi.uni-frankfurt.de; Phone: +49(0)69/79833811. 


\section{Introduction}

In the course of the recent global financial crisis central banks around the world have lowered nominal interest rates to record low levels. At the same time, many governments initiated fiscal stimulus programs intended to fight recession. This has led to a renewed interest in disentangling the roles of monetary and fiscal policy as stabilization tools in low interest rate environments.

In this paper, I study optimal monetary and fiscal policy in a stylized stochastic New Keynesian model that takes the zero nominal interest rate bound explicitly into account. The benevolent policymaker possesses two instruments, spending on public goods generating utility to consumers and the short-term nominal interest rate. Adverse shocks occasionally force the policymaker to drive nominal interest rates to zero. The model is solved with a global solution method and used to explore the implications of the zero bound for the optimal monetary and fiscal stabilization policy mix, the equilibrium responses of the economy to exogenous shocks, and private agents' welfare under alternative discretionary and commitment policies.

I provide both, qualitatively and quantitatively new results. It is well-known that the zero bound imposes a major constraint on the ability of monetary policy to stabilize the economy if the policymaker is unable to commit to future state-contingent policy actions (e.g. Adam and Billi, 2007; Nakov, 2008). I show that fiscal stabilization policy eliminates to a large extent the welfare costs associated with the presence of the zero lower bound. For a standard calibration to the US economy, the unconditional welfare loss in the model with zero bound does not differ much from the loss generated in a model that ignores the zero bound.

Under the optimal discretionary policy, government spending is raised above the level consistent with the efficient equilibrium whenever the zero bound becomes binding, thereby mitigating the drop in the output gap and the inflation rate. In normal times, only monetary policy is used to stabilize the economy. Nevertheless, fiscal policy also affects the equilibrium responses of the macroeconomic variables when the nominal interest rate is positive. Adam and Billi (2007) and Nakov (2008) show that the asymmetry in the capability of discretionary monetary policy to counteract expansionary and contractionary disturbances in the presence of the zero bound creates a deflationary bias in private sector expectations. With active fiscal policy, private agents anticipate that expansions in government 
spending will be used to stabilize the economy in states with zero nominal interest rates. This mitigates the bias in agents' expectations, thereby improving the policymaker's stabilization performance in all states and reducing the likelihood of zero bound events.

The welfare gains from discretionary fiscal policy can be enhanced by the appointment of an activist policymaker who puts less weight on stabilizing government spending than the private sector does. Intuitively, under discretion, the policymaker does not take into account how her actions affect private agents' expectations when solving her optimization problem. The appointment of an activist policymaker allows us to exploit the welfare-improving effect of active fiscal stabilization policy at the zero bound on the equilibrium dynamics in normal times despite the lack of a commitment device.

Under commitment, the welfare gains from active fiscal policy are negligible. Qualitatively, at the zero lower bound the optimal policy plan prescribes the implementation of a transitory government spending stimulus, which is followed by a fiscal retrenchment. In comparison to the case where only monetary policy is used as a stabilization tool, allowing for active fiscal policy dampens the required amount of costly above-target inflation promised to be delivered in the future.

The paper can be related to several studies on optimal monetary policy in the presence of the zero lower bound that solve fully stochastic models but abstract from fiscal stabilization policy. Adam and Billi (2006, 2007) and Nakov (2008) characterize optimal monetary policy in forward-looking New Keynesian models with occasionally binding zero lower bound and show that it is important to take the stochastic nature of the economy into account, whereas Orphanides and Wieland (2000) and Kato and Nishiyama (2005) study optimal monetary policy in backward-looking stochastic models. Billi (2011) compares the optimal long-run inflation rate under commitment and under discretion. Bodenstein et al. (2012) consider optimal monetary policy under imperfect credibility. ${ }^{1}$ Model-based experiments on fiscal policy at the zero bound have mainly centered on the fiscal multiplier, see e.g. Cogan et al. (2010), Christiano et al. (2011), Woodford (2011), and Coenen et al. (2012). An exception is Mankiw and Weinzierl (2011) who examine optimal monetary and fiscal policy in a deterministic two-period model with short-term nominal rigidities. Instead, this paper determines optimal monetary and fiscal policy in a fully stochastic forward-looking infinite-horizon model, thereby taking into account eco-

\footnotetext{
${ }^{1}$ Eggertsson and Woodford (2003) characterize optimal monetary policy for an economy with two states in which some deterministic shock has pushed nominal interest rates to zero in the initial period, and there is a constant probability to return forever to the non-crisis state in the subsequent periods. Jung et al. (2005) and Levin et al. (2010) study optimal monetary policy at the zero bound in the standard New Keynesian model under perfect foresight.
} 
nomic uncertainty and its interactions with the zero lower bound.

The remainder of the paper is organized as follows. Section 2 introduces the model environment. Section 3 characterizes optimal discretionary monetary and fiscal policy. Optimal policy plans under commitment are considered in section 4. Section 5 presents the welfare analysis. Section 6 examines the desirability of a discretionary policymaker who puts less weight on stabilizing government spending than the private sector does. The sensitivity analysis is conducted in section 7 . Finally, section 8 concludes.

\section{The model}

The economy is represented by a stylized New Keynesian model as described in detail in e.g. Woodford (2003) that has been widely used for policy analysis. The representative household consumes composite private and public consumption goods and supplies labor to the production sector, where utility is separable in all three arguments as in Woodford (2011). ${ }^{2}$ Firms employ industry-specific labor and use a constant-return-to-scale technology to produce differentiated goods that can be used for private or public consumption. They act under monopolistic competition and are subject to staggered price-setting as in Calvo (1983). The policymaker attempts to maximize the expected lifetime utility of the representative household. She decides about the level of government spending on the public consumption good and about the one-period nominal interest rate, where the latter is constrained by the zero lower bound. Government expenditures are financed by lump-sum taxes. Time is discrete and indexed by $t$. A detailed description of the model is provided in the online appendix to this paper. ${ }^{3}$

\footnotetext{
${ }^{2}$ I am considering a cashless limiting economy in the sense of Woodford (2003), abstracting from the role of monetary frictions. Eggertsson and Woodford (2003) show for a model similar to the one used here that the optimal stabilization policy can be analyzed without an explicit treatment of central bank open-market operations.

${ }^{3}$ The online appendix is available from http://www.sebastianschmidt.eu and upon request from the author.
} 


\subsection{Private sector behavior}

The optimization problems of the representative household and goods-producing firms result in the following behavioral constraints

$$
\begin{aligned}
\hat{\pi}_{t} & =\kappa\left(\hat{Y}_{t}^{g a p}-\Gamma \hat{G}_{t}^{g a p}\right)+\beta E_{t} \hat{\pi}_{t+1}+u_{t} \\
\hat{Y}_{t}^{\text {gap }} & =\hat{G}_{t}^{\text {gap }}+E_{t} \hat{Y}_{t+1}^{\text {gap }}-E_{t} \hat{G}_{t+1}^{\text {gap }}-\sigma\left(\hat{R}_{t}-E_{t} \hat{\pi}_{t+1}\right)+d_{t} .
\end{aligned}
$$

Equation (1) is a New Keynesian Phillips curve originating from firms' profit maximization, and Equation (2) is a dynamic IS curve originating from the representative household's intertemporal optimization. The model equations have been log-linearized around the non-stochastic steady state with the gross inflation rate set equal to 1 . Variables with a hat are expressed in percentage deviations from steady state, where $\hat{\pi}_{t}$ denotes the inflation rate, $\hat{Y}_{t}^{\text {gap }}$ represents the output gap, $\hat{G}_{t}^{g a p}$ is the government spending gap expressed as a share of steady state output and $\hat{R}_{t}$ denotes the nominal interest rate between period $t$ and $t+1$. The output gap is defined as the difference between the actual level of output and the level of output consistent with the efficient equilibrium. ${ }^{4}$ Similarly, the government spending gap is defined as the difference between actual government spending and the level of government spending consistent with the efficient equilibrium.

The parameter $\beta \in(0,1)$ denotes the subjective discount factor and $\sigma>0$ is the inverse of the elasticity of the marginal utility of private consumption with respect to total output. The parameters $\kappa$ and $\Gamma$ are functions of the structural parameters

$$
\kappa=\frac{(1-\alpha)(1-\alpha \beta)}{\alpha(1+\eta \theta)}\left(\sigma^{-1}+\eta\right), \quad \Gamma=\frac{\sigma^{-1}}{\sigma^{-1}+\eta},
$$

where $\alpha \in(0,1)$ denotes the share of firms that cannot reoptimize their price in a given period, $\eta>0$ denotes the inverse of the elasticity of labor supply, and $\theta>1$ represents the steady state of the price elasticity of demand for differentiated goods.

The model economy is subject to two composite shocks, both following stationary autoregressive

\footnotetext{
${ }^{4}$ I assume that the distortions arising from monopolistic competition in the non-stochastic steady state are offset by an appropriate wage subsidy, so that the non-stochastic flexible-price steady state corresponds to the efficient steady state.
} 
processes

$$
\begin{aligned}
& u_{t}=\rho_{u} u_{t-1}+\epsilon_{t}^{u} \\
& d_{t}=\rho_{d} d_{t-1}+\epsilon_{t}^{d},
\end{aligned}
$$

where $\epsilon_{t}^{j}, j \in\{u, d\}$ are $i . i . d . \mathrm{N}\left(0, \sigma_{j}^{2}\right)$ innovations. Here, $u_{t}$ is an inefficient supply disturbance representing price markup shocks, and $d_{t}$ captures variations in the real interest rate consistent with the efficient equilibrium $r_{t}^{*}$, henceforth referred to as the efficient real rate of interest

$$
\begin{aligned}
u_{t} & =-\frac{\kappa}{(\theta-1)\left(\sigma^{-1}+\eta\right)} \log \left(\theta_{t} / \theta\right) \\
d_{t} & =\sigma\left(r_{t}^{*}-r^{*}\right)
\end{aligned}
$$

where $r^{*}=\frac{1}{\beta}-1$ denotes the steady state of the efficient real interest rate. ${ }^{5}$ Finally, it provides useful to define the level of the nominal interest rate as $i_{t} \equiv \hat{R}_{t}+r^{*}$.

\subsection{The policy objective}

The policymaker's objective function originates from a linear-quadratic approximation to household welfare $^{6}$

$$
L_{0}=E_{0} \sum_{t=0}^{\infty} \beta^{t} \frac{1}{2}\left[\hat{\pi}_{t}^{2}+\lambda\left(\hat{Y}_{t}^{g a p}-\Gamma \hat{G}_{t}^{g a p}\right)^{2}+\lambda_{G}\left(\hat{G}_{t}^{g a p}\right)^{2}\right]
$$

The relative weights $\lambda, \lambda_{G}$ are functions of the structural parameters

$$
\lambda=\frac{\kappa}{\theta}, \quad \lambda_{G}=\lambda \Gamma\left(1-\Gamma+\frac{\sigma}{\omega}\right)
$$

where $\omega$ denotes the inverse of the elasticity of the marginal utility of public consumption with respect to total output.

\footnotetext{
${ }^{5}$ The efficient real rate of interest is a function of preference and technology shocks, though, to facilitate computation I do not consider the relative importance of these shocks for the fluctuations in the efficient real rate. Further details are provided in the online appendix.

${ }^{6}$ The details of the derivation are provided in the online appendix. Levin et al. (2010) show in the context of a perfectforesight model with monetary commitment that the optimality conditions for the linear-quadratic problem are equivalent to a first-order approximation of the optimality conditions for the non-linear policy problem.
} 


\subsection{Calibration}

The model economy is calibrated to the US economy. The parameterization follows Woodford (2003) and Adam and Billi $(2006,2007)$, and is summarized in Table 1. The period length is one quarter. Two

Table 1: Calibration

\begin{tabular}{lll}
\hline Parameter & Value & Economic interpretation \\
\hline$r^{*}$ & $3.5 / 4$ & Steady state efficient rate of interest (in \%) \\
$\beta$ & 0.9913 & Discount factor \\
$G / Y$ & 0.2 & Steady state share of government spending in total output \\
$\alpha$ & 0.66 & Share of firms per period keeping prices unchanged \\
$\theta$ & 7.66 & Price elasticity of demand in the steady state \\
$\eta$ & 0.47 & Elasticity of real marginal costs with respect to the firm's own output level \\
$\sigma$ & 6.25 & Inverse elasticity of marginal utility of private consumption w.r.t. total output \\
$\omega$ & 1.56 & Inverse elasticity of marginal utility of public consumption w.r.t. total output \\
$\kappa$ & 0.0244 & New Keynesian Phillips curve parameter \\
$\rho_{u}$ & 0 & AR-coefficient cost-push shock \\
$\rho_{d}$ & 0.8 & AR-coefficient efficient real rate shock \\
$S d\left(\epsilon_{t}^{u}\right)$ & 0.154 & Standard deviation cost-push shock innovation (in \%) \\
$S d\left(\epsilon_{t}^{d}\right)$ & 1.524 & Standard deviation efficient rate shock innovation (in \%) \\
$\lambda$ & 0.0032 & Loss function weight I \\
$\lambda_{G}$ & 0.0038 & Loss function weight II \\
\hline
\end{tabular}

additional parameters have to be calibrated, the steady state ratio of government spending to real GDP $G / Y$ and the elasticity of the marginal utility of public good consumption with respect to total output $\omega^{-1}$. Following Galí et al. (2007) and Christiano et al. (2011), the steady state share of government spending in total output is set equal to 20 percent, a standard value for the US economy. In the baseline calibration, the parameter $\omega$ is chosen such that the intertemporal elasticity of substitution in public consumption equals the intertemporal elasticity of substitution in private consumption as in Woodford (2011), however, different parameter values of $\omega$ are considered in the sensitivity analysis section.

\section{Optimal policy under discretion}

I first determine the optimal policy under discretion. Optimal plans for monetary and fiscal policy are considered in the subsequent section. Without commitment, the policymaker is unable to manipulate beliefs about future policy and therefore takes private sector expectations as given when solving her 
optimization problem. ${ }^{7}$ Each period $t$, the policymaker chooses inflation, the output gap, the government spending gap and the nominal interest rate to minimize her objective function subject to the zero nominal interest rate bound and the behavioral constraints

$$
\begin{aligned}
& \min _{\hat{\pi}_{t}, \hat{Y}_{t}^{\text {gap }}, \hat{G}_{t}^{\text {gap }}, \hat{R}_{t}} E_{t} \sum_{j=0}^{\infty} \beta^{j} \frac{1}{2}\left[\hat{\pi}_{t+j}^{2}+\lambda\left(\hat{Y}_{t+j}^{\text {gap }}-\Gamma \hat{G}_{t+j}^{\text {gap }}\right)^{2}+\lambda_{G}\left(\hat{G}_{t+j}^{\text {gap }}\right)^{2}\right] \\
& \text { subject to } \\
& \hat{R}_{t} \geq-r^{*}
\end{aligned}
$$

Equations (1) - (4)

$$
\begin{aligned}
& u_{t}, d_{t} \text { given } \\
& \left\{\hat{\pi}_{t+j}, \hat{Y}_{t+j}^{g a p}, \hat{G}_{t+j}^{g a p}, \hat{R}_{t+j} \geq-r^{*}\right\} \text { given for } j \geq 1 .
\end{aligned}
$$

The consolidated first-order conditions read

$$
\begin{aligned}
(1-\Gamma)\left[\kappa \hat{\pi}_{t}+\lambda\left(\hat{Y}_{t}^{g a p}-\Gamma \hat{G}_{t}^{g a p}\right)\right]+\lambda_{G} \hat{G}_{t}^{\text {gap }} & =0 \\
\left(\hat{R}_{t}+r^{*}\right)\left[\kappa \hat{\pi}_{t}+\lambda\left(\hat{Y}_{t}^{g a p}-\Gamma \hat{G}_{t}^{g a p}\right)\right] & =0 \\
\hat{R}_{t} & \geq-r^{*} \\
\kappa \hat{\pi}_{t}+\lambda\left(\hat{Y}_{t}^{g a p}-\Gamma \hat{G}_{t}^{\text {gap }}\right) & \leq 0 .
\end{aligned}
$$

If the zero lower bound on the nominal interest rate is not binding, condition (11) has to hold with equality. Conditions (8) and (11) then imply that only monetary policy is used as a stabilization tool, whereas the government spending gap remains closed $\hat{G}_{t}^{\text {gap }}=0$. There are two reasons why monetary policy is preferred to fiscal policy in normal times. First, variations in the nominal interest rate unlike variations in the government spending gap do not by themselves create welfare costs. Second, even if monetary policy is unable to completely stabilize inflation and the output gap, as is the case in the face of price markup shocks, government spending is a less efficient stabilization tool than the short-term nominal interest rate. Consider an inflationary cost-push shock. If the policymaker uses the fiscal policy instrument to dampen the rise in the inflation rate, she must reduce the level of

\footnotetext{
${ }^{7}$ I consider Markov-perfect equilibria. The policymaker acts as Stackelberg leader and the private sector and future policymakers are Stackelberg followers.
} 
government spending. This lowers aggregate demand, labor demand declines and the equilibrium real wage falls, thereby counteracting the inflationary pressures. However, since the equilibrium hours of work decline, total output has to decrease. If the policymaker uses monetary policy, the increase in the nominal interest rate dampens private consumption. On the one hand this lowers aggregate demand, triggering the same transmission mechanism as before, but on the other hand the fall in private consumption ceteris paribus increases households' labor supply. In equilibrium, hours worked, and hence total output, have to fall by less than would be the case under fiscal stabilization policy. ${ }^{8}$ However, when the zero lower bound renders nominal interest rate policy ineffective, fiscal policy is used to stabilize the economy. In particular, from (8) and (11) follows

$$
\hat{G}_{t}^{g a p}=-\frac{1-\Gamma}{\lambda \Gamma \frac{\sigma}{\omega}}\left[\kappa \hat{\pi}_{t}+\lambda \hat{Y}_{t}^{g a p}\right] \geq 0
$$

The rational expectations equilibrium under optimal discretionary monetary and fiscal policy is then characterized by policy functions $\hat{\pi}\left(u_{t}, d_{t}\right), \hat{Y}^{g a p}\left(u_{t}, d_{t}\right), \hat{G}^{g a p}\left(u_{t}, d_{t}\right)$ and $\hat{R}\left(u_{t}, d_{t}\right)$ solving conditions (1) - (2), and (8) - (11). I use the collocation method to obtain approximations of the unknown policy functions. ${ }^{9}$ The algorithm is described in the online appendix. Under the linear-quadratic approach, the zero bound constraint is the only nonlinearity that is explicitly taken into account. The advantage of this approach is that it facilitates computation and allows for straightforward comparison with the literature on optimal policy without zero bound. ${ }^{10}$ Figure 1 shows equilibrium responses of the endogenous variables to the efficient real rate of interest for the baseline calibration. I consider two types of policy regimes, the baseline case with optimization over monetary and fiscal policy (labeled "With fiscal") and an alternative scenario with optimization over monetary policy only (labeled "No fiscal"). The non-stochastic steady state is the same for both regimes, but under the latter government spending is not used for stabilization policy, i.e. $\hat{G}_{t}^{g a p}=0$ for all $t$. The implications of active fiscal policy are twofold. First, for small realizations of the efficient real rate that lead to a

\footnotetext{
${ }^{8}$ Eser et al. (2009) show that the lack of a role for government spending stabilization policy is a quite general feature of optimal policy in New Keynesian models without zero interest rate bound that is robust to several model extensions.

${ }^{9}$ The collocation method allows us to take the uncertainty arriving from the stochastic nature of the efficient real rate shock and the markup shock correctly into account in that agents' expectations represent probability distributions over future economic outcomes. Earlier work by Adam and Billi $(2006,2007)$ and Nakov (2008) has shown that it is crucial not to abstract from this dimension of the problem in that the solution of the analogue perfect-foresight model considerably underestimates the welfare costs associated with the zero lower bound.

${ }^{10}$ See also the discussion in Adam and Billi (2006).
} 
Figure 1: Equilibrium responses to the efficient real rate of interest under discretion
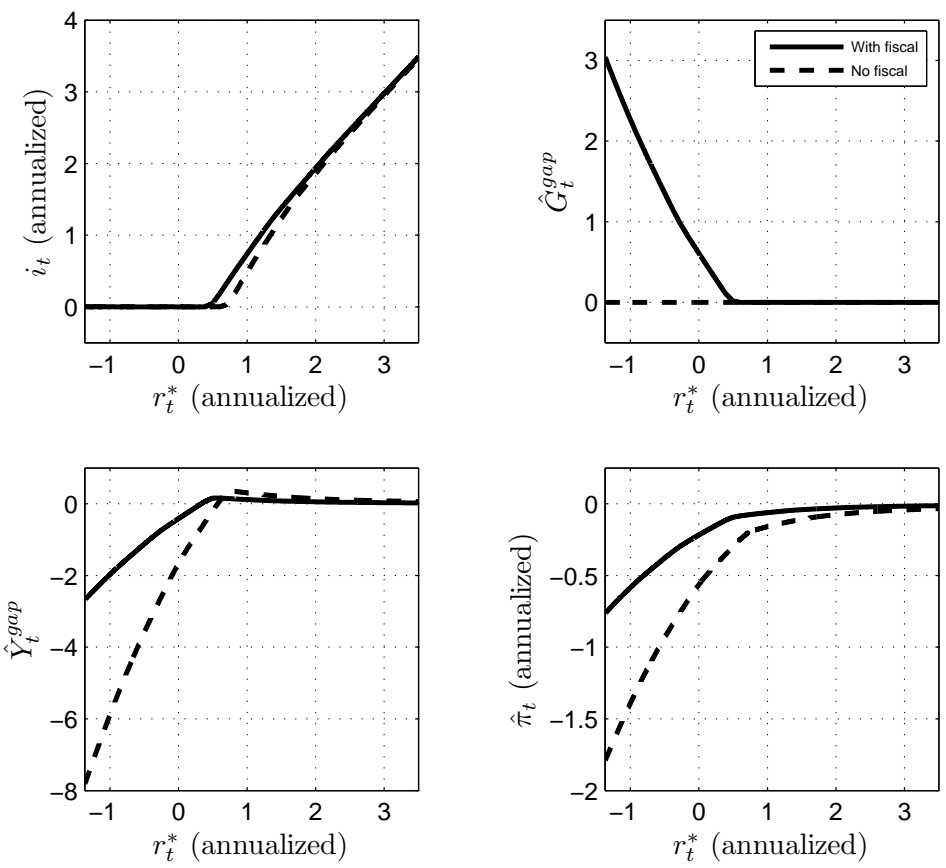

Notes: Equilibrium responses to the efficient real interest rate shock under optimal discretionary policy are shown for the baseline calibration. Inflation and interest rates are expressed in annualized percentage points. The value of the cost-push shock is set equal to zero.

binding zero bound constraint, fiscal stabilization policy attenuates the decline in the output gap and in the inflation rate compared to the constrained regime that relies only on monetary policy. Second, even though fiscal policy is only used as a stabilization tool at the zero floor, it also affects equilibrium responses when nominal interest rates are positive. In particular, note, that discretionary policy also fails to stabilize inflation and the output gap for realizations of the efficient real rate above the threshold below which the zero bound becomes binding. Adding the fiscal stabilization tool helps to dampen the inefficient responses of the output gap and the inflation rate. Specifically, fiscal policy reduces the adherent asymmetry in the capability of the public sector to counteract positive and negative shocks to the efficient real rate in low interest rate environments. While the policymaker is always able to raise nominal interest rates in order to offset positive shocks to the efficient real rate of interest, discretionary monetary policy looses power to stabilize inflation and output once a large enough negative rate shock occurs such that the zero bound becomes binding. This creates a deflationary bias in 
private agents' expectations. ${ }^{11}$ Incorporating fiscal stabilization policy, the private sector anticipates that government spending will respond to the shock once monetary policy becomes ineffective. This anticipation mitigates the bias in agents' expectations about future economic outcomes, leading to an improved stabilization performance. Importantly, the attenuation of the deflationary bias reduces the likelihood of zero lower bound events.

\section{Optimal policy under commitment}

This section determines optimal policy under commitment. The benevolent policymaker chooses state-contingent paths for inflation, the output gap, the government spending gap and the nominal interest rate to minimize her objective function subject to the zero nominal interest rate bound and the behavioral constraints

$$
\begin{aligned}
& \min _{\substack{\hat{\pi}_{t}, \hat{Y}_{t}^{\text {gap }}, \hat{G}_{t}^{\text {gap }}, \hat{R}_{t} \\
\text { subject to }}} E_{0} \sum_{t=0}^{\infty} \beta^{t} \frac{1}{2}\left[\hat{\pi}_{t}^{2}+\lambda\left(\hat{Y}_{t}^{\text {gap }}-\Gamma \hat{G}_{t}^{\text {gap }}\right)^{2}+\lambda_{G}\left(\hat{G}_{t}^{\text {gap }}\right)^{2}\right] \\
& \hat{R}_{t} \geq-r^{*}
\end{aligned}
$$$$
\text { Equations (1) - (4) }
$$$$
u_{0}, d_{0} \text { given, }
$$

\footnotetext{
${ }^{11}$ See Adam and Billi (2007) and Nakov (2008) for further discussion of the deflationary bias under discretionary policy.
} 
for all $t=0,1, \ldots, \infty$.

The resulting equilibrium conditions read

$$
\begin{aligned}
\hat{\pi}_{t}-\phi_{t}+\phi_{t-1}-\frac{\sigma}{\beta} \mu_{t-1} & =0 \\
\lambda\left(\hat{Y}_{t}^{g a p}-\Gamma \hat{G}_{t}^{g a p}\right)+\kappa \phi_{t}+\mu_{t}-\frac{1}{\beta} \mu_{t-1} & =0 \\
\frac{1-\Gamma}{\lambda_{G}}\left(\mu_{t}-\frac{1}{\beta} \mu_{t-1}\right) & =\hat{G}_{t}^{g a p} \\
\mu_{t} & \geq 0 \\
\hat{R}_{t} & \geq-r^{*} \\
\mu_{t}\left(\hat{R}_{t}+r^{*}\right) & =0,
\end{aligned}
$$

as well as (1) and (2), where $\phi_{t}$ and $\mu_{t}$ denote the Lagrange multipliers associated with the policy problem, and $\phi_{-1}, \mu_{-1}=0$. Under commitment, optimal policy introduces history dependence as reflected by the lagged Lagrange multipliers in (13) - (15). Equation (15) relates the government spending gap to the contemporaneous and lagged zero-lower-bound multipliers. The positive coefficient on the contemporaneous multiplier implies that the policymaker raises government spending above the level consistent with the efficient equilibrium when the nominal interest rate hits the zero lower bound. However, unlike in the discretionary regime, the fiscal stimulus is followed by a spending reversal, as shown by the negative coefficient on the lagged multiplier. Since $\frac{1}{\beta}>1$, it may well be that the fiscal retrenchment is implemented while the zero bound is still binding.

The rational expectations equilibrium under commitment is then characterized by policy functions $\hat{\pi}\left(\Omega_{t}\right), \hat{Y}^{\text {gap }}\left(\Omega_{t}\right), \hat{G}^{\text {gap }}\left(\Omega_{t}\right), \hat{R}\left(\Omega_{t}\right), \phi\left(\Omega_{t}\right)$ and $\mu\left(\Omega_{t}\right)$, with $\Omega_{t}=\left(u_{t}, d_{t}, \phi_{t-1}, \mu_{t-1}\right)$, solving (1) - (2) and (13) - (18). The numerical algorithm is described in the online appendix.

Figure 2 shows impulse responses to an efficient real interest rate shock of -3 unconditional standard deviations for the baseline calibration. ${ }^{12}$ The optimal monetary and fiscal policy plan is compared to the corresponding discretionary regime and to the constrained commitment regime which can only use monetary policy as a macroeconomic stabilization tool. In all three regimes, the shock drives

\footnotetext{
${ }^{12}$ I show impulse responses instead of equilibrium responses to characterize the commitment regime, since otherwise I would have to condition the responses to the efficient real rate on certain realizations of the two lagged commitment multipliers.
} 
Figure 2: Impulse responses to an efficient real rate shock
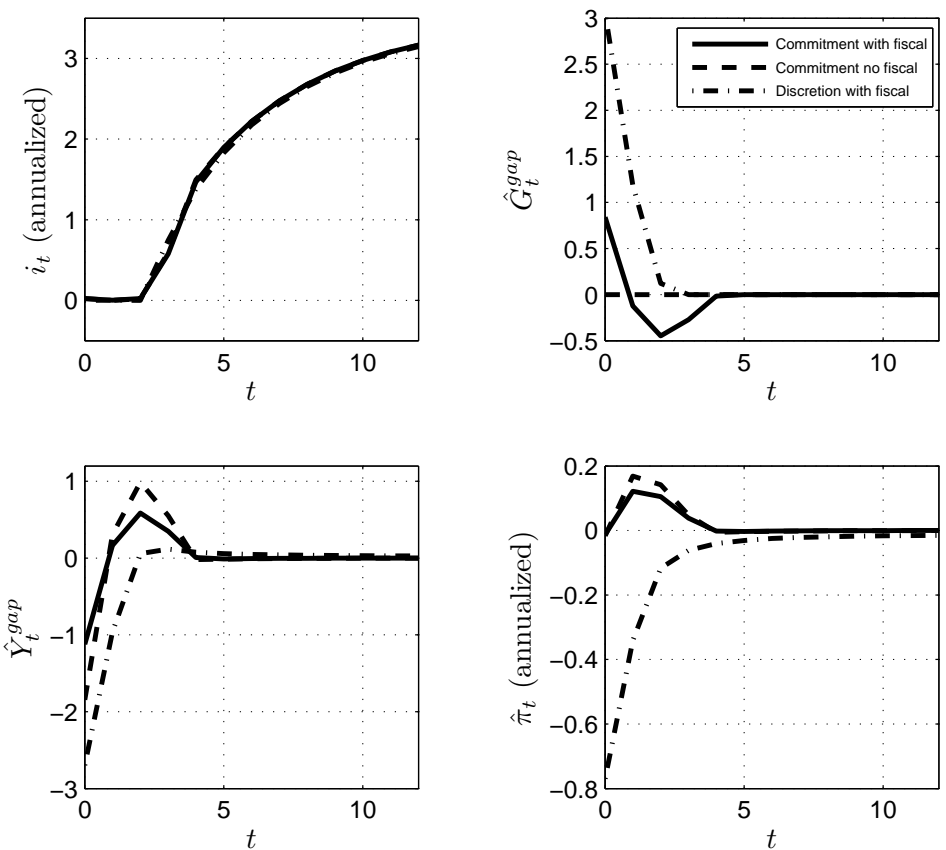

Notes: Impulse responses to an efficient real interest rate shock of -3 unconditional standard deviations are shown for the baseline calibration. Inflation and the nominal interest rate are expressed in annualized percentage points.

nominal interest rates to zero and output and inflation fall initially below their target levels. Under commitment, the policymaker promises to keep nominal interest rates low for long enough in order to create a transitory economic boom in subsequent periods. Accordingly, private agents' inflation expectations increase and real interest rates decline below zero, thereby mitigating the initial drop in the target variables compared to the discretionary regime. If the policymaker acting under commitment has two stabilization tools at her disposal, fiscal policy incurs some of the burden to stabilize the economy. In response to the shock, the policymaker initially raises government spending above the level consistent with the efficient equilibrium. The spending stimulus, which is smaller than under discretion, dampens the decline in aggregate demand and inflation. As a consequence, the optimal amount of costly above-target inflation promised to be delivered in the future is smaller than under the constrained commitment regime. In order to cushion the inflation boom the policymaker engineers a reversal in government spending. At this point, fiscal policy is preferred to monetary policy. Future levels of government spending have only an indirect effect on today's private consumption through 
their impact on the inflation path, whereas a less accommodative nominal interest rate policy would have a direct adverse effect on today's private consumption level through the intertemporal optimality condition of the representative household.

\section{Welfare analysis}

The previous sections have shown that endogenous government spending improves the ability of the public sector to stabilize inflation and the output gap in response to contracting shocks to the efficient real rate of interest. However, fiscal stabilization policy by itself creates costs. This section aims to quantify the overall welfare effects.

I calculate the average discounted welfare loss across 2000 simulations with a length of 1000 periods each. Table 2 reports the results for the baseline calibration. The first row of Table 2 presents the losses

Table 2: Welfare losses

\begin{tabular}{lccccc}
\hline \multirow{2}{*}{ Policy regime } & \multicolumn{3}{c}{ Discretion } & \multicolumn{2}{c}{ Commitment } \\
& No fiscal & With fiscal & Activist fiscal & No fiscal & With fiscal \\
\hline Equivalent consumption loss & 0.0285 & 0.0256 & 0.0254 & 0.0193 & 0.0192 \\
Loss increase with zero bound & $15.2 \%$ & $3.8 \%$ & $3.0 \%$ & $0.6 \%$ & $0.4 \%$ \\
\hline
\end{tabular}

Notes: The first row reports welfare losses expressed in terms of the equivalent permanent reduction in private consumption in percent of its non-stochastic steady state level. The second row reports the percentage increase in the consumption loss if the model takes the zero bound into account.

in terms of the equivalent permanent reduction in private consumption (in percent). ${ }^{13}$ The second row reports the costs associated with the presence of the zero bound in terms of the percentage increase in the consumption loss if the model takes the zero bound into account. If the policymaker is unable to commit to future policy actions and uses only monetary policy as a stabilization tool, then explicitly accounting for the presence of the zero bound leads to an increase in the unconditional welfare loss of about $15.2 \%$, where the zero bound constraint is binding in about 2.4 percent of the simulated periods. The picture changes once we allow for active fiscal policy. Employing government spending as an additional stabilization tool quarters the welfare costs associated with the presence of the zero bound under the discretionary policy regime and reduces the frequency of zero bound events to 2.1 percent.

\footnotetext{
${ }^{13}$ The transformation of the losses from objective function (7) into equivalent consumption losses is described in the online appendix.
} 
Importantly, the overall consumption loss under discretionary monetary and fiscal policy with zero bound is not much higher than the loss observed for discretionary policy when abstracting from the zero floor.

The welfare losses under policy commitment are reported in columns 4 and 5 of Table 2 . In this case, the introduction of fiscal stabilization policy has almost no effect on the overall stabilization performance. This is not surprising, given that the optimal monetary policy plan alone is already able to almost completely offset the welfare effects arising from the zero bound, as shown in the second row of Table 2.

Taken together, the previous results imply that the value of policy commitment, defined as the difference between the consumption losses under discretion and under commitment, is much lower if both monetary and fiscal policy are used as stabilization tools than in the case without active fiscal policy. Specifically, once we account for endogenous government spending, the value of policy commitment in the model with zero lower bound is not much higher than normally obtained when abstracting from the zero floor.

\section{Activist fiscal policy}

This section shows that, under discretion, the gains from fiscal stabilization policy can be enhanced by appointing a policymaker who puts less weight on stabilizing government spending than the private sector does.

Without commitment, the policy problem reduces to a sequence of static optimization problems. ${ }^{14}$ Hence, the discretionary policymaker ignores the welfare-improving effect of the fiscal stimulus at the zero lower bound on the stabilization performance in normal times. In the following, I replace the parameter $\lambda_{G}$ in the policymaker's objective function (7) by the parameter $\tilde{\lambda}_{G}>\lambda \Gamma(1-\Gamma)$ which may differ from society's weight on the stabilization of government purchases. Figure 3 displays the costs associated with the zero bound in terms of the increase in the consumption loss if the model takes the zero bound into account for alternative values of $\tilde{\lambda}_{G}$, evaluated using the weight $\lambda_{G}$. The outcome in the baseline case where the policymaker and private agents put the same weight on the stabilization

\footnotetext{
${ }^{14}$ Note, that the model exhibits no endogenous state variable under the discretionary regime.
} 
Figure 3: Loss increase under discretionary policy if the zero bound is taken into account

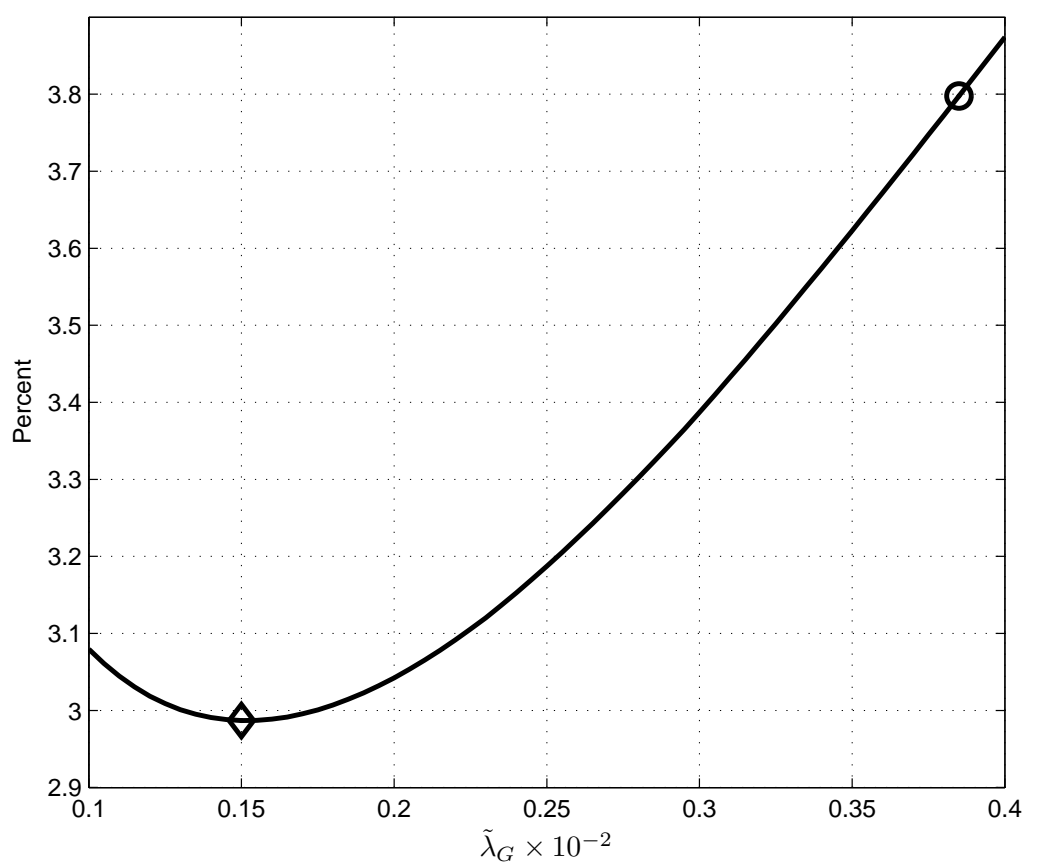

Notes: The figure displays the increase in consumption losses under discretionary policy if the model takes the zero nominal interest rate bound into account for alternative values of the weight on government spending gap stabilization in the policymaker's objective function, $\tilde{\lambda}_{G}$. The circle denotes the outcome when $\tilde{\lambda}_{G}=\lambda_{G}$. The smallest loss increase is denoted by a diamond.

of government purchases is denoted by a circle. The best-performing discretionary policymaker, denoted by a diamond, however, puts a smaller weight on the stabilization of government purchases. The corresponding consumption loss is reported in the third column of Table 2 labeled "Activist fiscal." Whenever the zero bound becomes binding, the activist policymaker raises the government spending gap by more than in the baseline case. At that time, the more-active policy is not welfare optimal since the costs of the additional fiscal stimulus outweigh the mitigated decline in the output gap and in the inflation rate. However, the improved stabilization performance in normal times which itself makes zero bound events less likely, leads to an overall reduction of the unconditional welfare loss. 


\section{Sensitivity analysis}

This section examines to which extent the welfare results obtained under the baseline calibration are robust to changes in parameter values.

Recent studies have argued that research based on macroeconomic models estimated for the Great Moderation period might have underestimated the likelihood and the severity of zero bound events, see e.g. Chung et al. (2012). One way to address this issue is to consider the welfare effects from lowering the steady state efficient real rate of interest $r^{*}$. Figure 4 displays the increase in the consumption loss if the model takes the zero lower bound into account for alternative values of $r^{*}$. The

Figure 4: Loss increase if the zero bound is taken into account
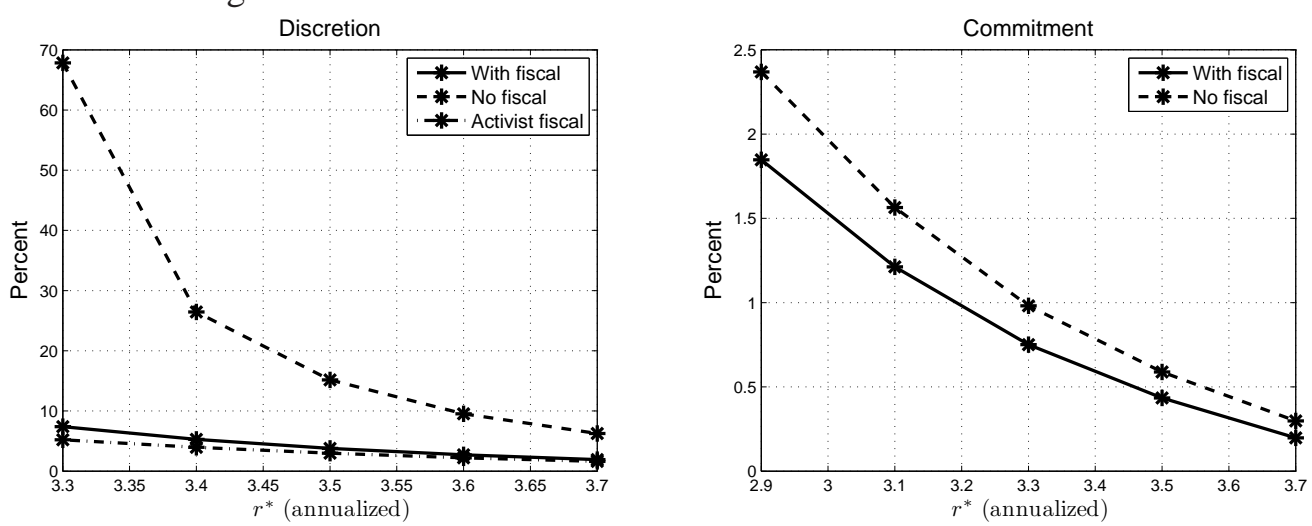

Notes: The figure displays the increase in consumption losses if the model takes the zero nominal interest rate bound into account for alternative values of the steady state level of the efficient real rate of interest, $r^{*}$. The left panel shows the results for the discretionary policy regimes and the right panel shows the results for the commitment regimes.

left panel displays the welfare implications for optimal discretionary policy, considering three alternative cases: the unconstrained regime, the constrained regime that employs only the monetary policy tool, and the unconstrained regime with activist fiscal policy, where $\tilde{\lambda}_{G}$ is chosen optimally. ${ }^{15}$ For all three regimes, the welfare costs associated with the existence of the zero bound increase when $r^{*}$ is lowered. However, while the two regimes that allow for fiscal stabilization policy experience only modest loss increases, the performance of the constrained regime without fiscal policy deteriorates considerably. The right panel of Figure 4 displays the welfare loss increases for the two commitment cases: the unconstrained regime and the constrained regime without fiscal policy. Lowering the steady

\footnotetext{
${ }^{15}$ When varying $r^{*}$, the subjective discount factor $\beta$ is adjusted accordingly. For $r^{*}$ below 3.3 percentage points (annualized), the numerical algorithm for the constrained discretionary regime does not converge.
} 
state of the efficient real rate has only minor effects on the performance of a policymaker who can commit to state-contingent plans.

A parameter of special interest is the inverse of the elasticity of the marginal utility of public good consumption with respect to total output $\omega$. The parameterization of $\omega$ does only affect the performance of the unconstrained regime. Figure 5 displays the increase in the consumption loss under discretion if the model takes the zero bound into account for alternative values of $\omega$ ranging from 0.1 to $3 .{ }^{16}$ The steady state private consumption to output ratio is held constant at the baseline value of 0.8. When monetary and fiscal policy are both used as stabilization tools, the welfare costs associated

Figure 5: Loss increase under discretionary policy if the zero bound is taken into account

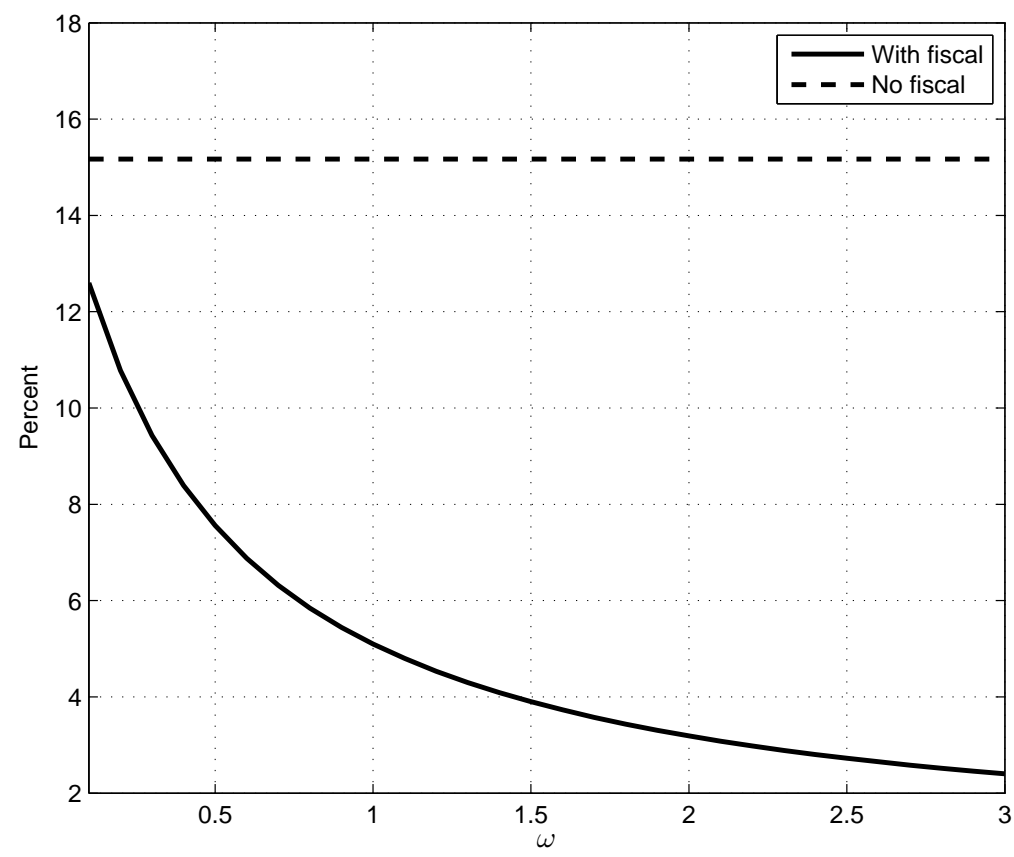

Notes: The figure displays the increase in consumption losses under discretionary policy if the model takes the zero nominal interest rate bound into account for alternative values of the inverse of the elasticity of the marginal utility of public good consumption with respect to total output, $\omega$.

with the presence of the zero bound shrink with rising $\omega$. On the other hand, when $\omega$ approaches zero, the welfare costs come closer to those of the constrained regime.

\footnotetext{
${ }^{16}$ Results for the commitment regime are not shown since in this case the zero bound imposes only negligible welfare costs on monetary policy.
} 


\section{Conclusion}

This paper determines optimal monetary and fiscal policy under discretion and under commitment in a small stochastic New Keynesian model with a zero lower bound on nominal interest rates. Under both policy regimes, fiscal policy is part of the optimal stabilization policy mix during zero bound episodes. Under discretion, using government spending as a second policy instrument in addition to the shortterm nominal interest rate eliminates to a large extent the - otherwise potentially substantial - welfare costs associated with the presence of the zero bound. The welfare gains from fiscal stabilization policy can be enhanced by the appointment of an activist policymaker who puts less weight on the stabilization of government spending than the private sector does. Under commitment, the welfare gains from fiscal stabilization policy remain small. When the policymaker is able to credibly commit to state-contingent future policy actions, monetary policy alone is able to offset most of the adverse effects arising from the zero lower bound.

The analysis in this paper relies on a stylized model that has been widely used for policy analysis. An important avenue for future work would be to extend the analysis to more complex medium-scale macroeconomic models and to compare the gains from fiscal stabilization policy to those of other policy measures that have been considered in the recent financial crisis, such as a higher inflation target and unconventional monetary policy tools.

\section{References}

Adam, Klaus, and Roberto M. Billi. (2006). "Optimal monetary policy under commitment with a zero bound on nominal interest rates.” Journal of Money, Credit and Banking 38(7), 1877-1905.

Adam, Klaus, and Roberto M. Billi. (2007). "Discretionary monetary policy and the zero lower bound on nominal interest rates." Journal of Monetary Economics 54, 728-752.

Billi, Roberto M. (2011). "Optimal inflation for the U.S. economy." American Economic Journal: Macroeconomics 3(3), 29-52.

Bodenstein, Martin, James Hebden, and Ricardo Nunes. (2012). "Imperfect Credibility and the Zero Lower Bound on the Nominal Interest Rate.” Journal of Monetary Economics 59, 135-149. 
Calvo, Guillermo. (1983). "Staggered contracts in a utility-maximizing framework." Journal of Monetary Economics 12, 383-398.

Christiano, Lawrence, Martin Eichenbaum, and Sergio Rebelo. (2011) "When is the government spending multiplier large?" Journal of Political Economy 119(1), 78-121.

Chung, Hess, Jean-Phillipe Laforte, David Reifschneider, and John C. Williams. (2012). "Have we underestimated the likelihood and severity of zero lower bound events?" Journal of Money, Credit and Banking 44, 47-82.

Coenen, Guenter, Christopher Erceg, Charles Freedman, Davide Furceri, Michael Kumhof, Ren Lalonde, Douglas Laxton, Jesper Lind, Annabelle Mourougane, Dirk Muir, Susanna Mursula, Carlos de Resende, John Roberts, Werner Roeger, Stephen Snudden, Mathias Trabandt and Jan in 't Veld. (2012). "Effects of Fiscal Stimulus in Structural Models." American Economic Journal: Macroeconomics 4(1), 22-68.

Cogan, John, Tobias Cwik, John B. Taylor, and Volker Wieland. (2010). "New Keynesian versus old Keynesian government spending multipliers." Journal of Economic Dynamics and Control 43, 281-295.

Eggertsson, Gauti, and Michael Woodford. (2003). "The Zero Bound on Interest Rates and Optimal Monetary Policy." Brookings Papers on Economic Activity 1, 139-211.

Eser, Fabian, Campbell Leith, and Simon Wren-Lewis. (2009). "When is Monetary Policy all we need?" University of Oxford, Department of Economics Discussion Paper 430.

Galí, Jordi, David López-Salido, and Javier Vallés. (2007). “Understanding the Effects of Government Spending on Consumption." Journal of the European Economic Association 5(1), 227-270.

Jung, Taehun, Yuki Teranishi, and Tsutomu Watanabe. (2005). "Optimal Monetary Policy at the ZeroInterest-Rate Bound." Journal of Money, Credit, and Banking 37(5), 813-835.

Kato, Ryo, and Shin-Ichi Nishiyama. (2005). "Optimal monetary policy when interest rates are bounded at zero." Journal of Economic Dynamics and Control 29, 97-133. 
Levin, Andrew, David López-Salido, Edward Nelson, and Tack Yun. (2010). "Limitations on the Effectiveness of Forward Guidance at the Zero Lower Bound." International Journal of Central Banking 6(1), 143-189.

Mankiw, N. Gregory, and Matthew C. Weinzierl. (2011). “An Exploration of Optimal Stabilization Policy." Brookings Papers on Economic Activity 42(1), 209-272.

Nakov, Anton. (2008). "Optimal and Simple Monetary Policy Rules with Zero Floor on the Nominal Interest Rate.” International Journal of Central Banking 4(2), 73-127.

Orphanides, Athanasios, and Volker Wieland. (2000). "Efficient Monetary Policy Design near Price Stability." Journal of the Japanese and International Economies 14, 327-365.

Woodford, Michael. (2003). Interest and Prices: Foundations of a Theory of Monetary Policy. Princeton: Princeton University Press.

Woodford, Michael. (2011). "Simple Analytics of the Government Expenditure Multiplier." American Economic Journal: Macroeconomics 3(1), 1-35. 